\title{
Biomimetic Synthesis of Antireflective
}

\section{Silica/Polymer Composite Coatings Comprising}

\section{Vesicular Nanostructures}

Ting-Xuan Lin, ${ }^{\dagger}$ Feng-Ming Hsu, ${ }^{\dagger}$ Yun-Lun Lee, ${ }^{\dagger}$ Raita Goseki, ${ }^{\ddagger}$ Takashi Ishizone ${ }^{\ddagger}$ and Jeng-Shiung $\operatorname{Jan}^{\dagger *}$

†Department of Chemical Engineering, National Cheng Kung University

No 1, University Rd., Tainan 70101, Taiwan

Department of Organic and Polymeric Materials, Tokyo Institute of Technology

2-12-1-S1-13 Ohokayama, Meguro-ku, Tokyo 152-8552 Japan 
Table S1. Characterization of poly(Z-L-lysine) (PZLL), poly( $\gamma$-benzyl glutamate) (PBLG), and polystyrene-block-poly(Z-L-lysine) (PS-b-PZLL) by GPC analysis.

\begin{tabular}{|c|c|c|c|c|}
\hline Polymer & [PS]: [ZLL NCA] & $\mathbf{M}_{\mathbf{n}}$ & $\mathbf{M}_{\mathbf{w}} / \mathbf{M}_{\mathbf{n}}$ & DP \\
\hline $\mathrm{PS}_{100}$ & --- & 9800 & 1.04 & 100 \\
\hline$\left(\mathrm{PS}_{100}\right)_{2}$ & --- & 21,000 & 1.04 & 100 \\
\hline $\mathrm{PS}_{100}-b-\mathrm{PZLL} 50$ & $1: 50$ & 23,000 & 1.21 & $51(\mathrm{ZLL})$ \\
\hline$\left(\mathrm{PS}_{100}\right)_{2}-b-\mathrm{PZLL} 50$ & $1: 50$ & 35,100 & 1.16 & $52(\mathrm{ZLL})$ \\
\hline $\mathrm{PBLG}_{75}$ & --- & 17,100 & 1.37 & 75 \\
\hline PZLL65 & --- & 16,900 & 1.28 & 65 \\
\hline
\end{tabular}


(a)<smiles>CCCCC1C(C)(C)CCC1(C)C</smiles><smiles>CN1CCC(C)(C)C1CCCCC(C)(C)C</smiles>



(b)

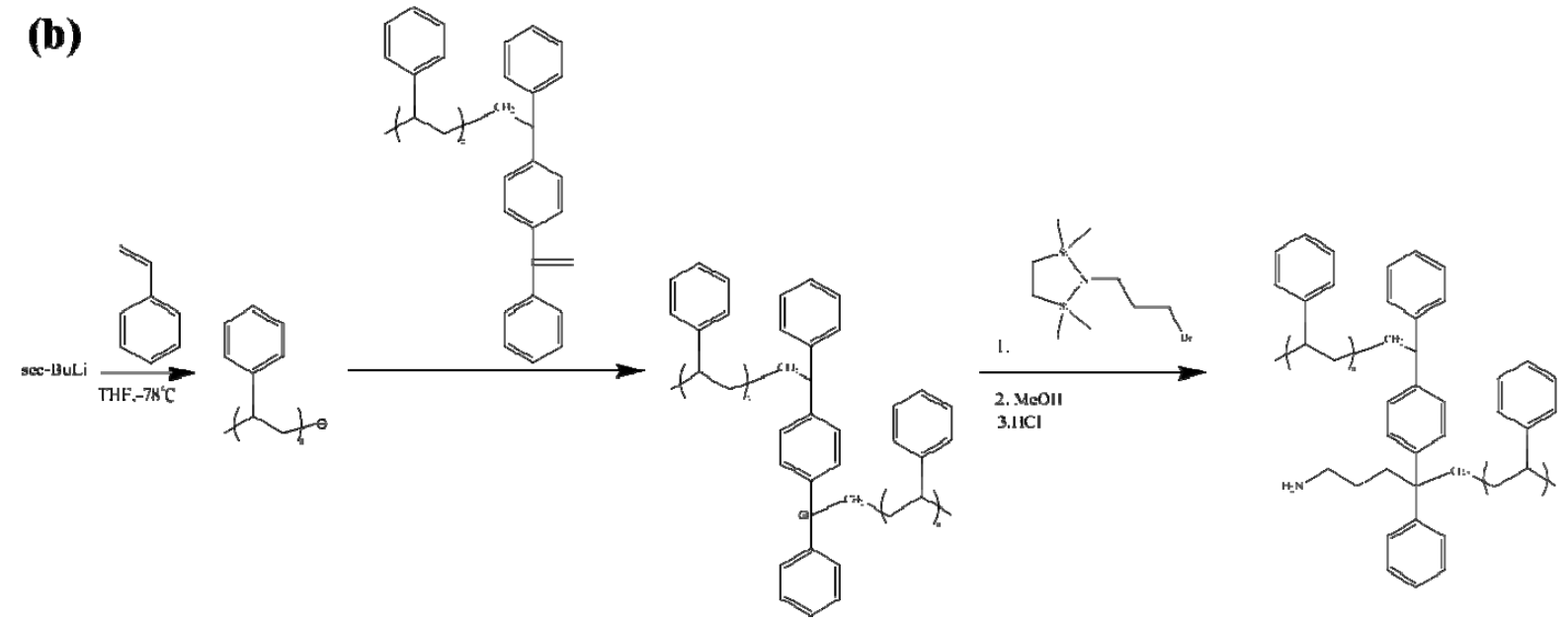

Scheme S1. Synthesis scheme of (a) $\mathrm{PS}_{100}-\mathrm{NH}_{2}$ and (b) $\left(\mathrm{PS}_{100}\right)_{2}-\mathrm{NH}_{2}$ amine functionalized polystyrene. 
(a)

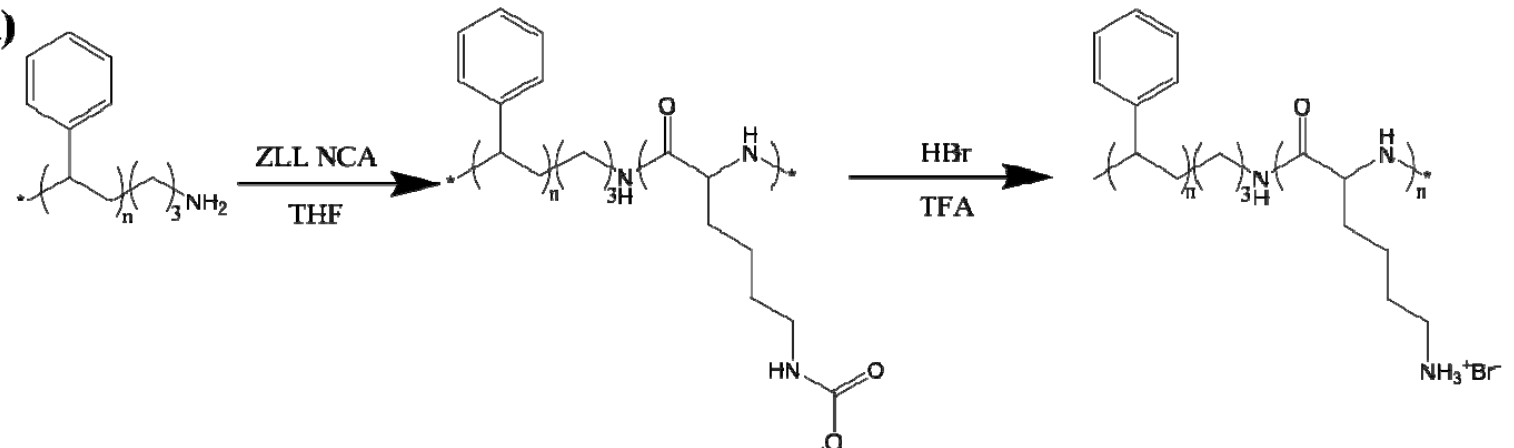

(b)

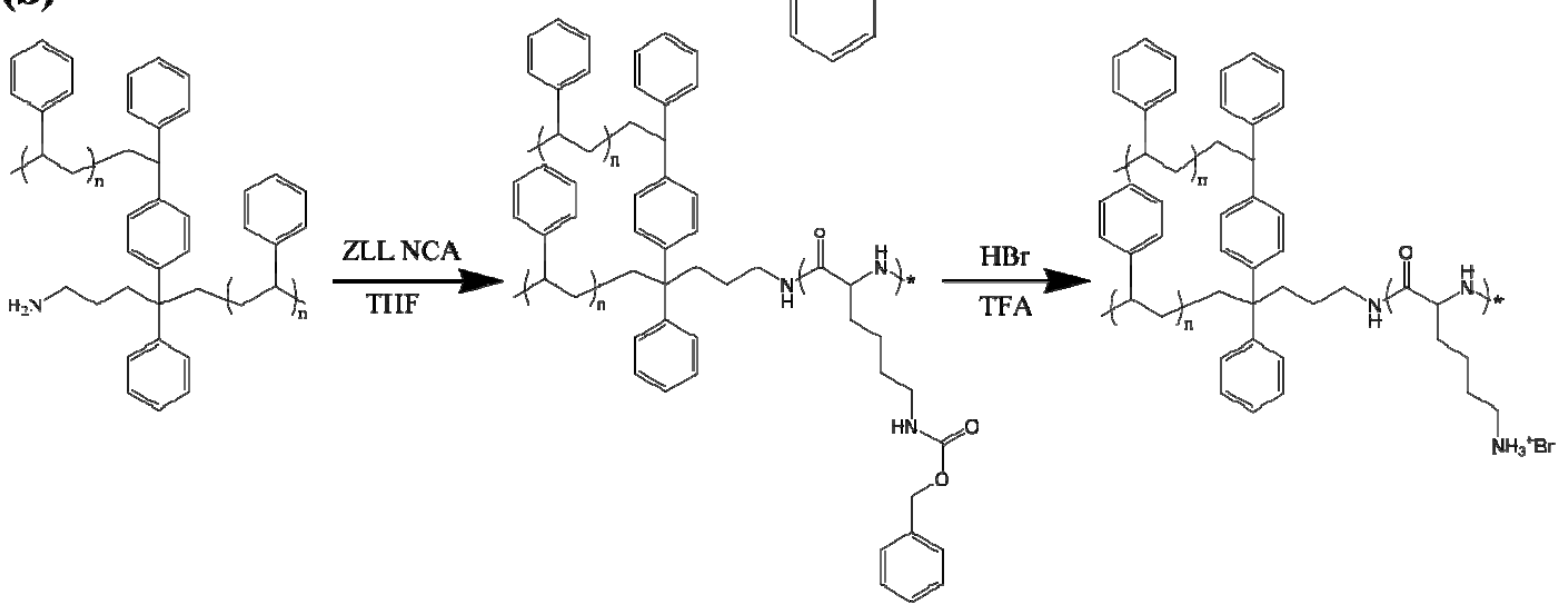

Scheme S2. Synthesis scheme of (a) PS $100-b$-PLL50 and (b) $\left(\mathrm{PS}_{100}\right)_{2}-b$-PLL50 block copolymers. 


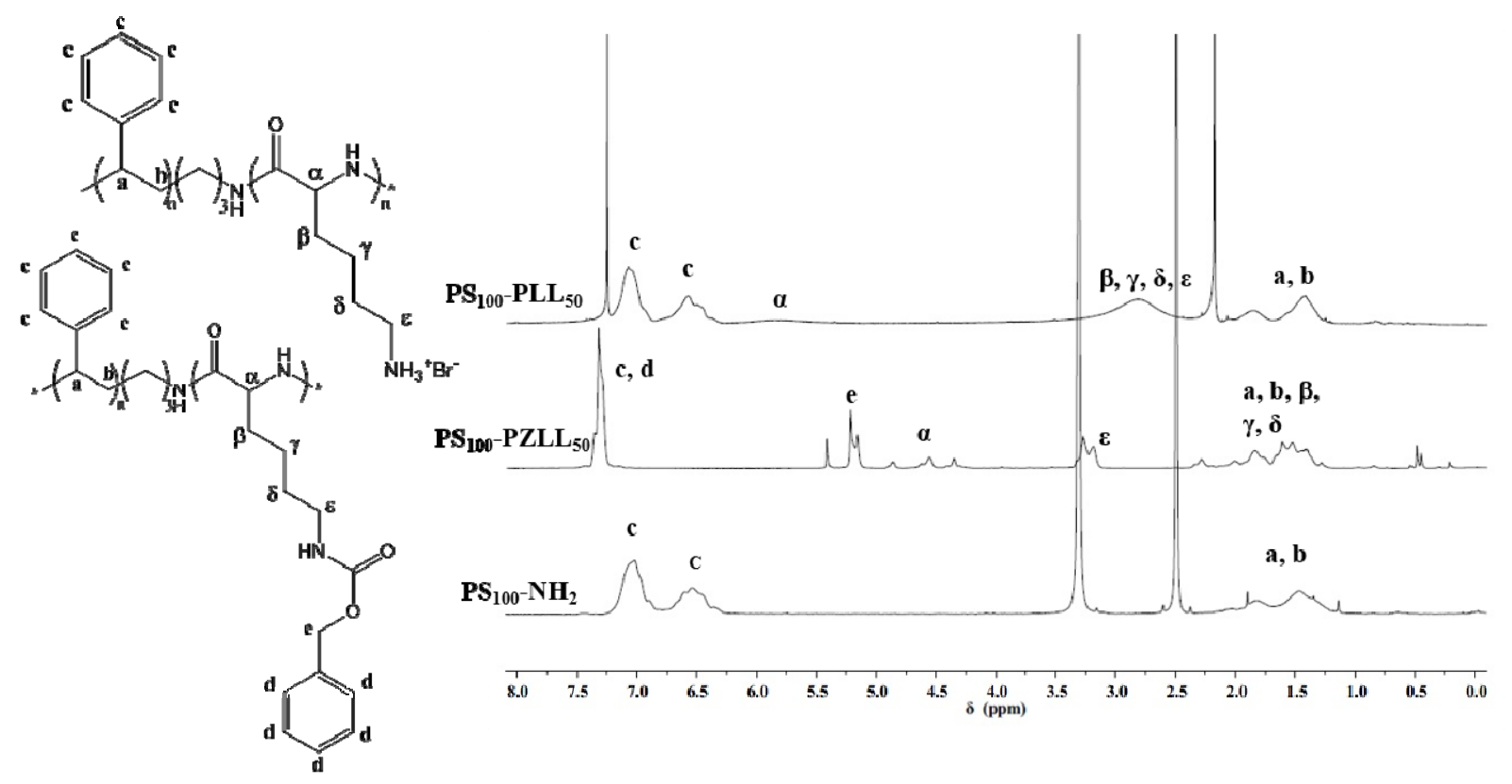

Figure S1. ${ }^{1} \mathrm{H}$ NMR spectra of $\mathrm{PS}_{100}-\mathrm{NH}_{2}$ in DMSO- $d_{6}, \mathrm{PS}_{100}-b-\mathrm{PZLL} 50$ in TFA- $d_{1}$, and (c) $\mathrm{PS}_{100}-b-\mathrm{PLL}_{50}$ in $\mathrm{CDCl}_{3}$. 

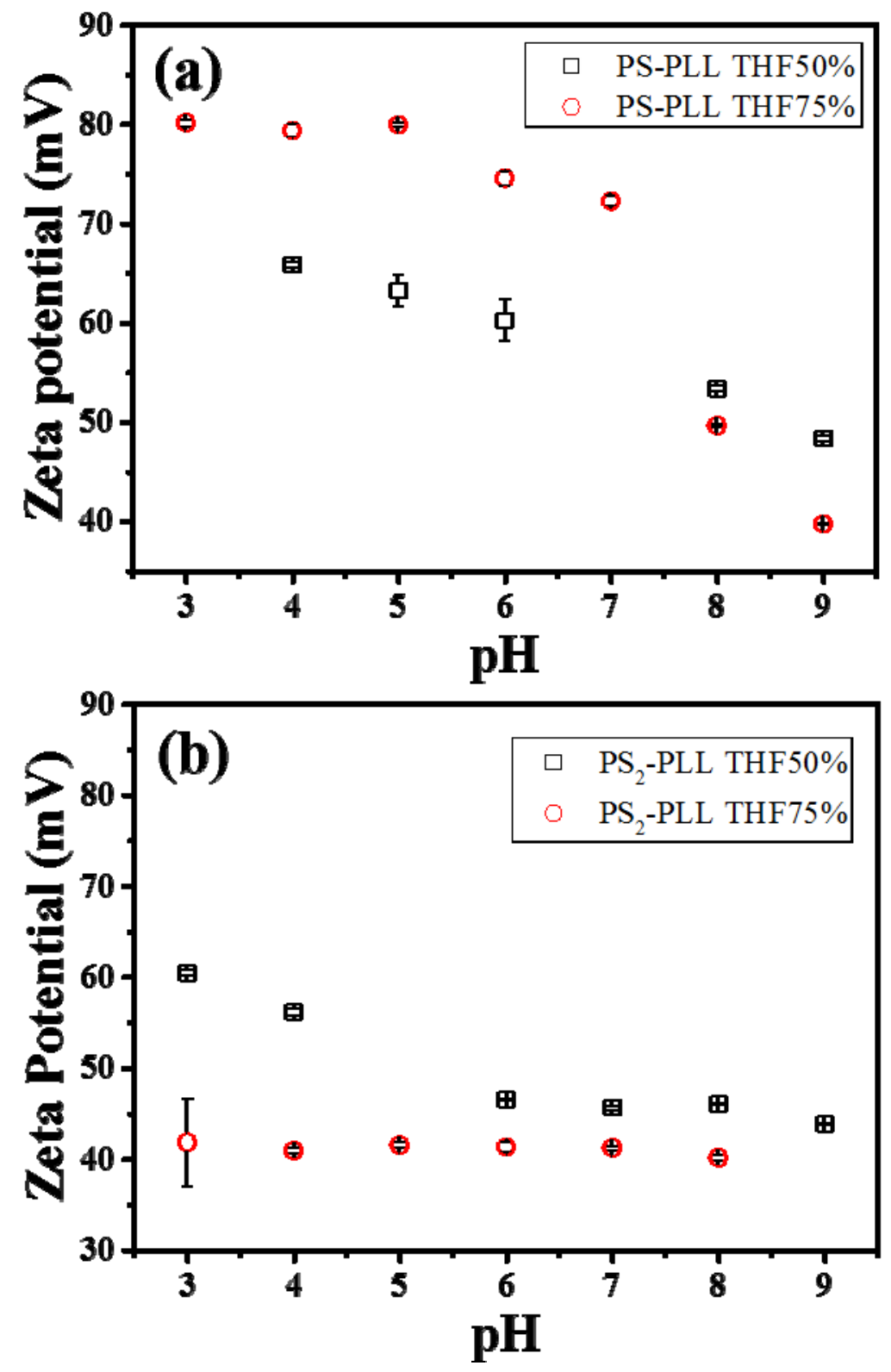

Figure S2. Zeta potential of PS100- $b$-PLL50 and (PS100) 2 - $b$-PLL50 assemblies as a function of solution $\mathrm{pH}(\mathrm{n}=3)$. The $\mathrm{PS}_{100}-b$-PLL50 and $\left(\mathrm{PS}_{100}\right)_{2}-b$-PLL50 assemblies were prepared at 50 and $75 \mathrm{v} / \mathrm{v} \%$ of THF volume percentages, respectively. 


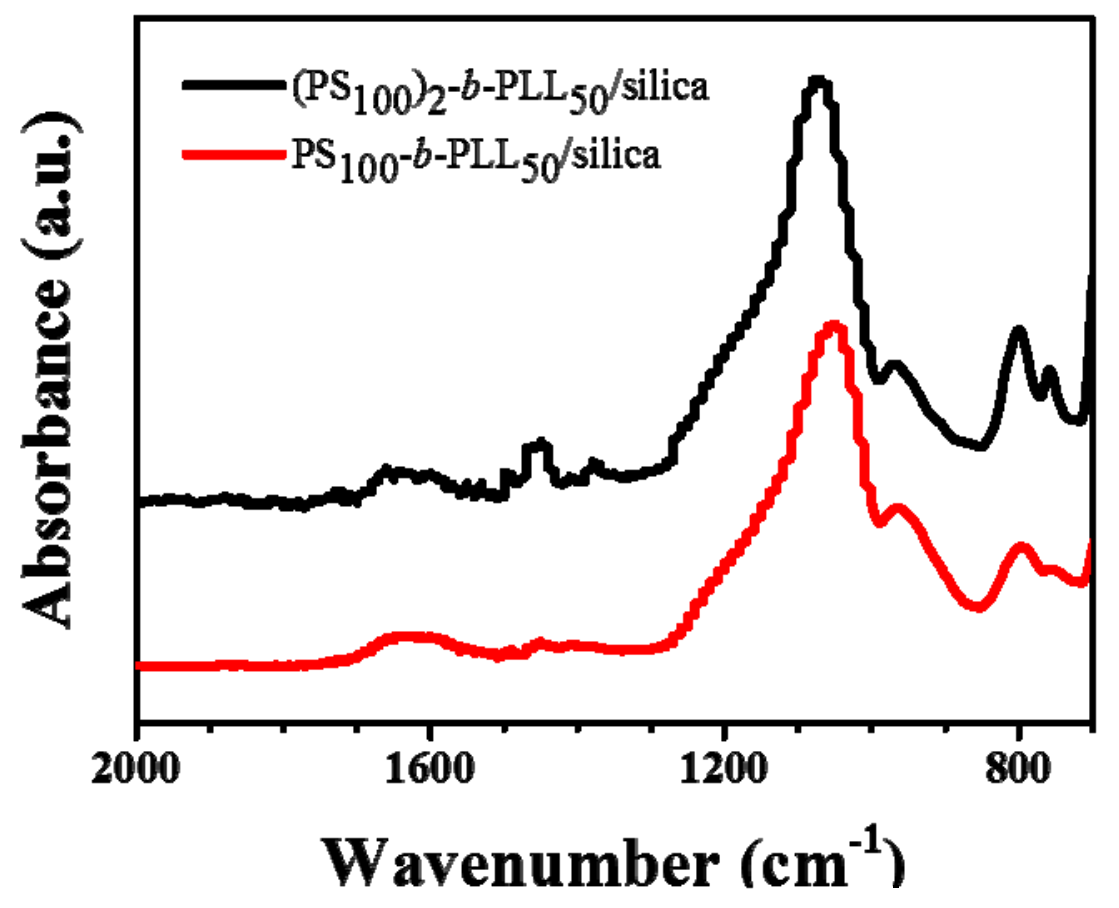

Figure S3. FTIR spectra of silica/PS $100-b$-PLL50 and silica/(PS 100$)_{2}-b$-PLL50 composite assemblies. The PS100- $b$-PLL50 and $\left(\mathrm{PS}_{100}\right)_{2}-b$-PLL50 assemblies were prepared at 50 and 75 v/v \% of THF volume percentages, respectively. 


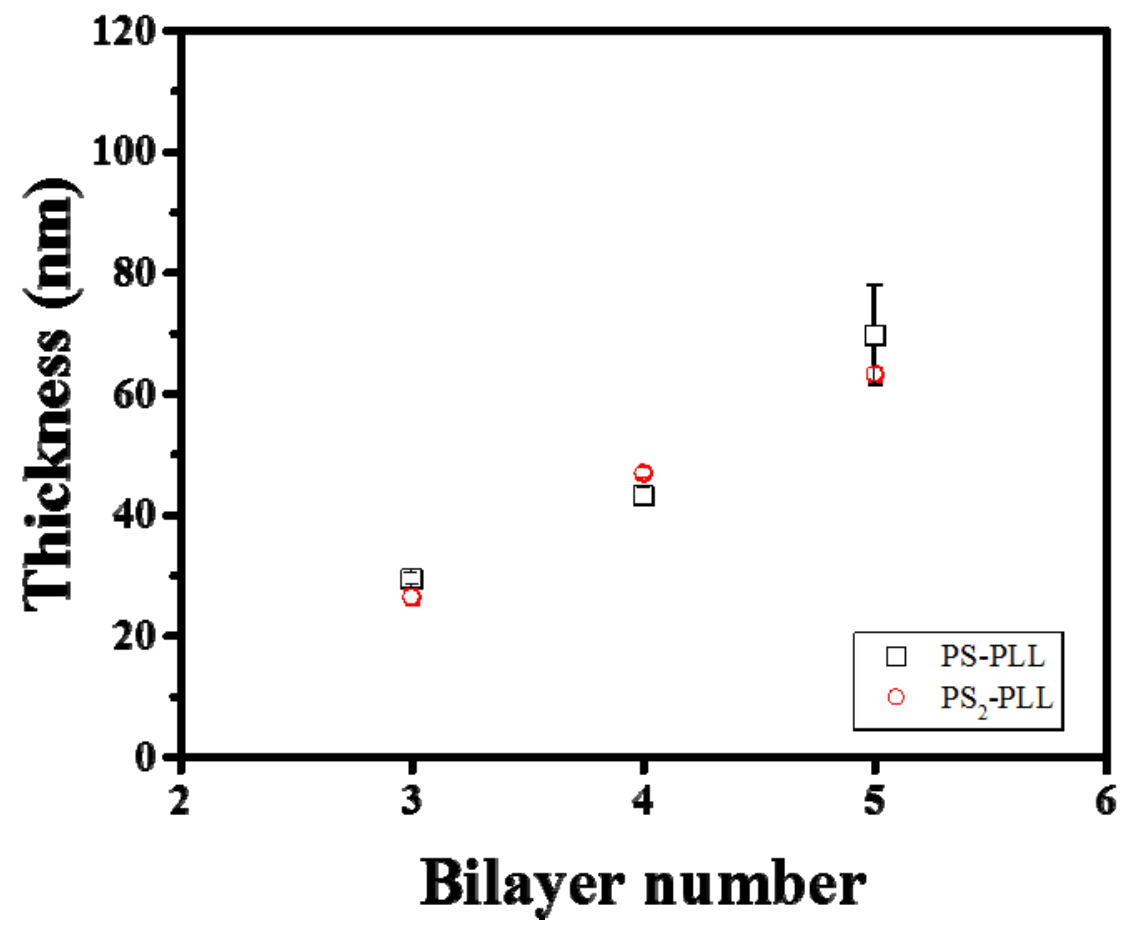

Figure S4. Film thickness of $\left(\mathrm{PS}_{100}-b-\mathrm{PLL}_{50} / \mathrm{PGA}_{75}\right)_{\mathrm{m}}$ and $\left(\left(\mathrm{PS}_{100}\right)_{2}-b-\mathrm{PLL}{ }_{50} / \mathrm{PGA}_{75}\right)_{\mathrm{m}}$ multilayer films as a function of number of bilayers (m). 


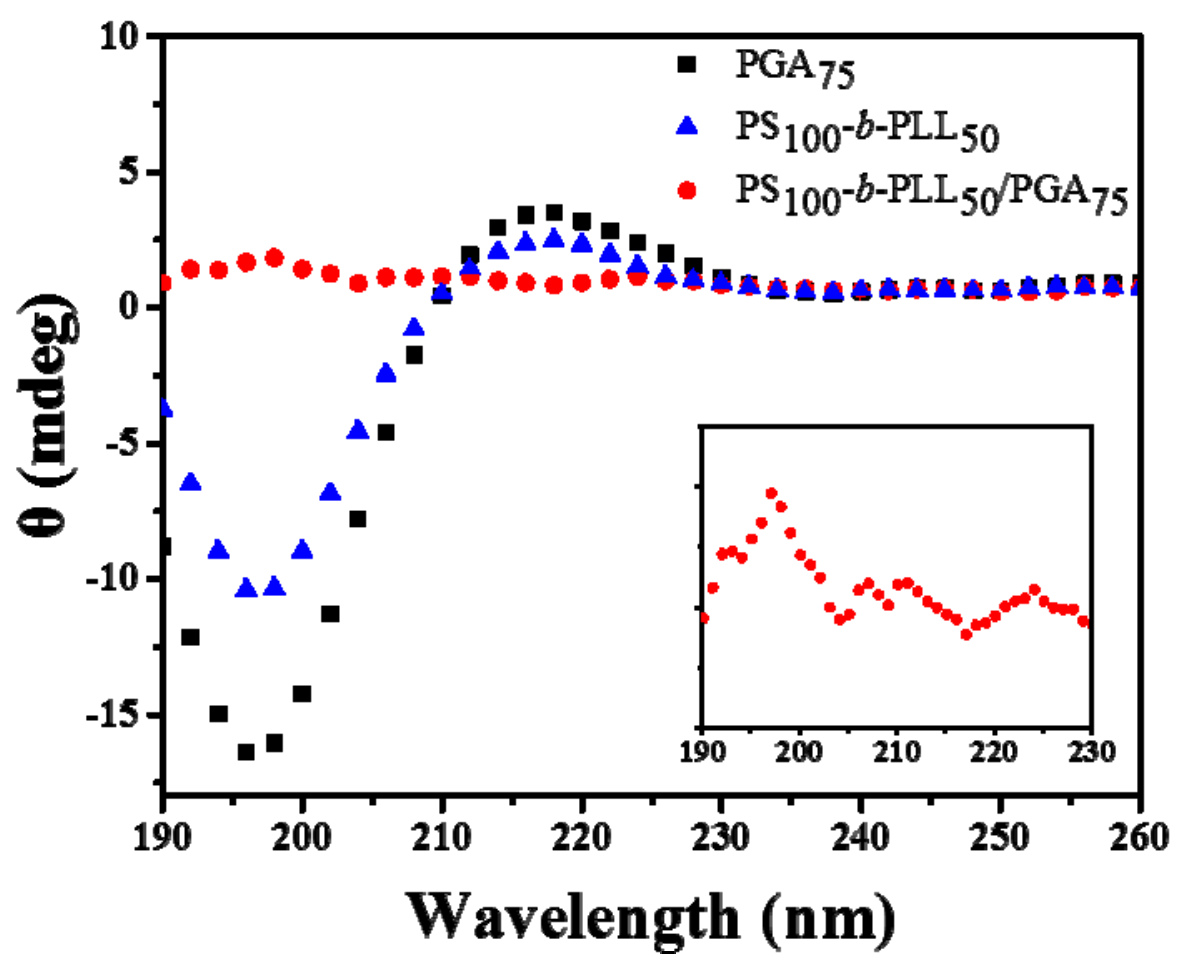

Figure S5. CD spectra of $\mathrm{PS}_{100}-b-\mathrm{PLL}_{50}$ assemblies, PGA75, and PS100- $b$-PLL50/PGA75 complexes. 


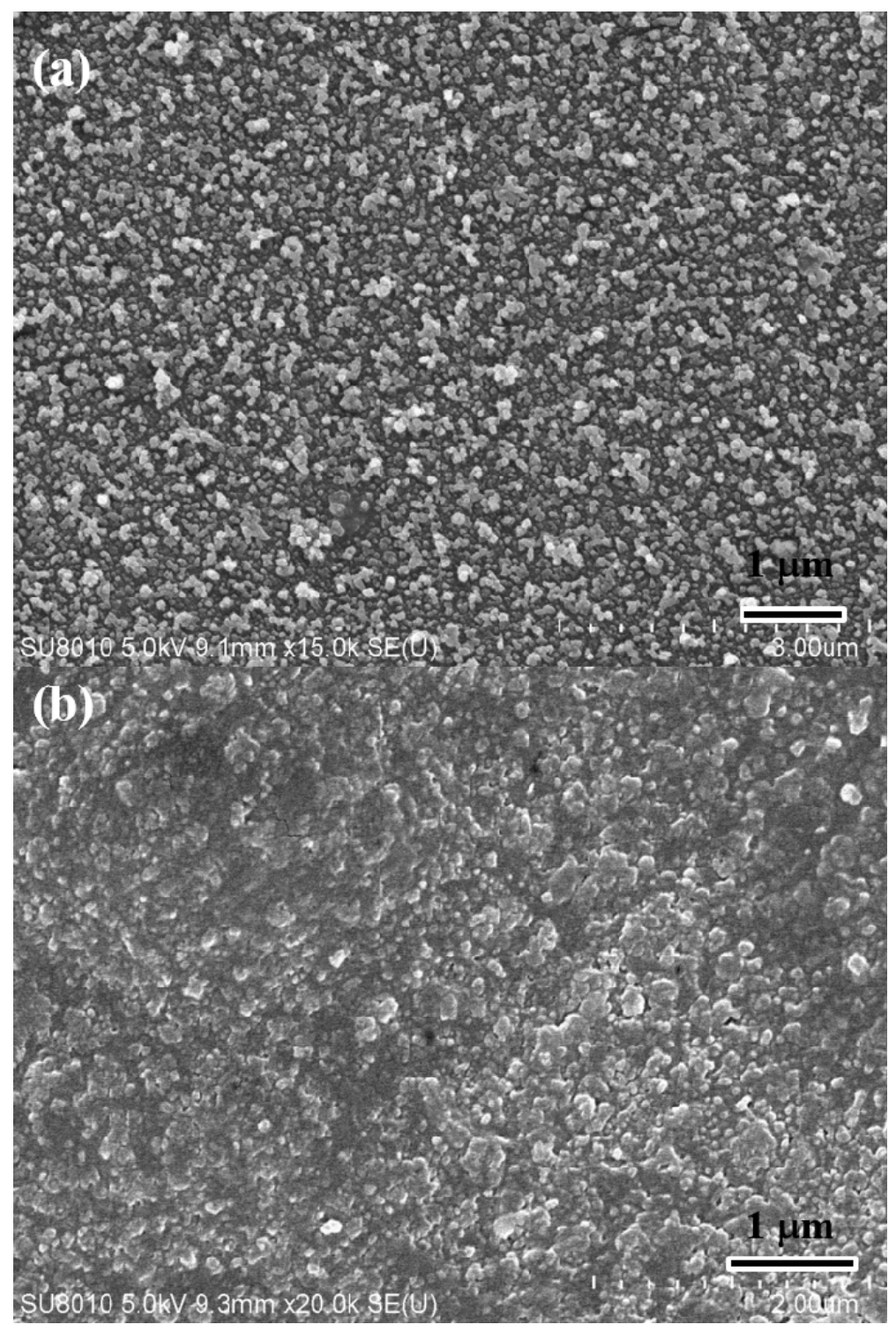

Figure S6. SEM images of the top view of (a) silica/(PS $\left.100-b-\mathrm{PLL}_{50} / \mathrm{PGA}_{75}\right)_{4}$ and (b) silica/((PS 100$)_{2}-b$-PLL50/PGA75)4 composite films coated onto PMMA substrate. 


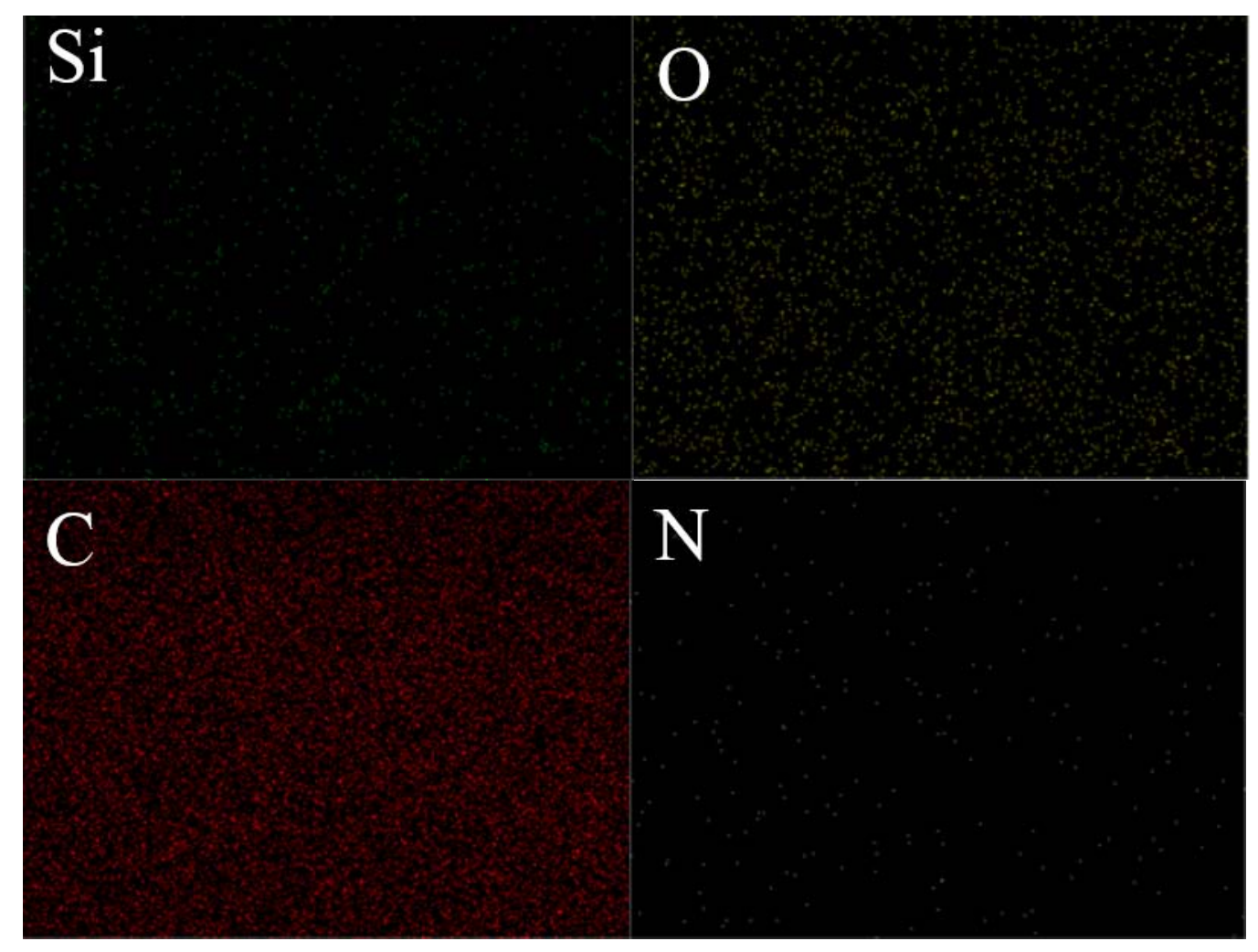

Figure S7. EDX analysis of silica/(PS $\left.100-b-\mathrm{PLL}_{50} / \mathrm{PGA}_{75}\right)_{4}$ composite films coated onto PMMA substrate. 


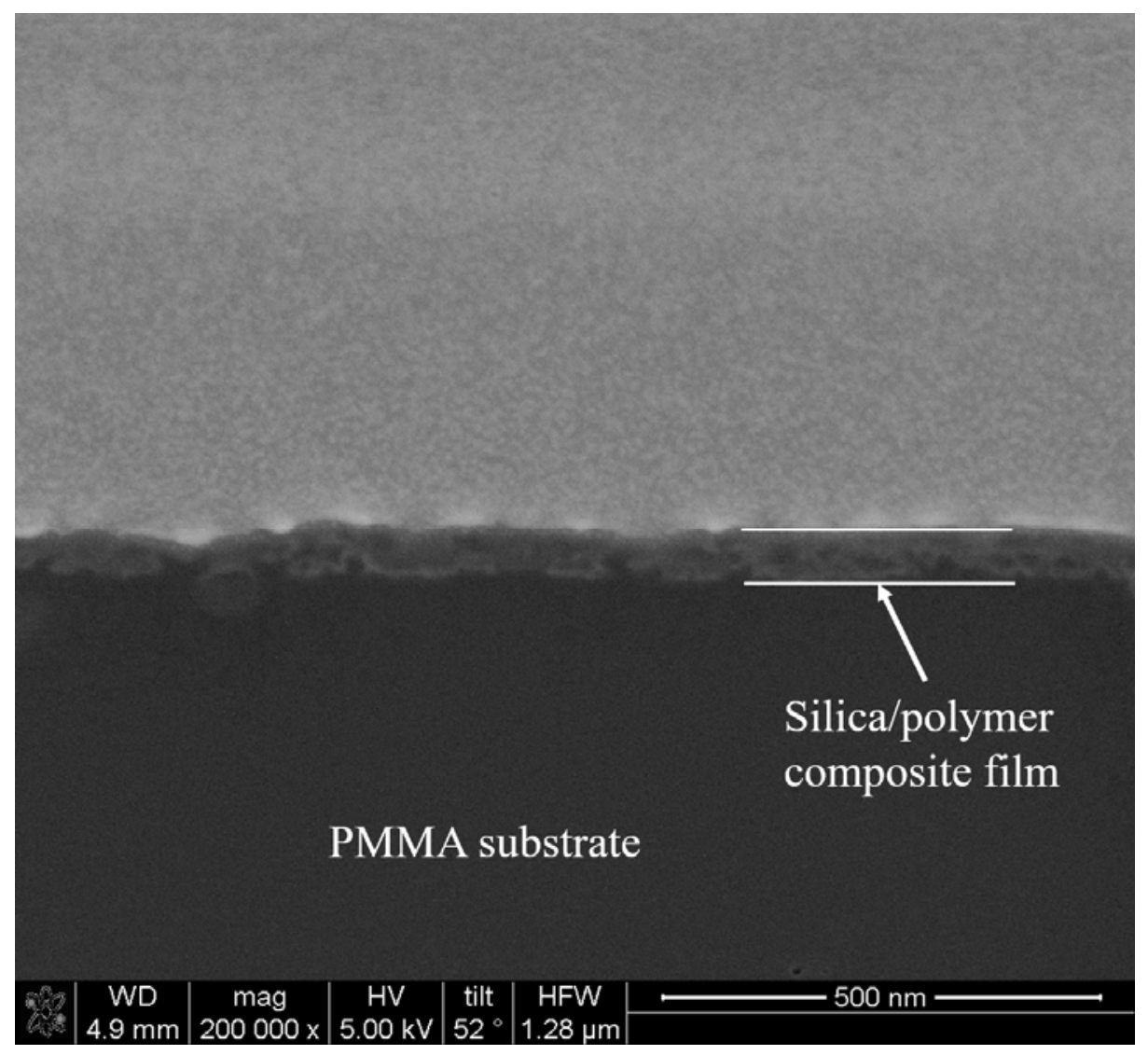

Figure S8. SEM image of the cross-sectional view of silica/(PS $\left.100-b-\mathrm{PLL}_{50} / \mathrm{PGA}_{75}\right)_{4}$ composite film coated onto PMMA substrate. 

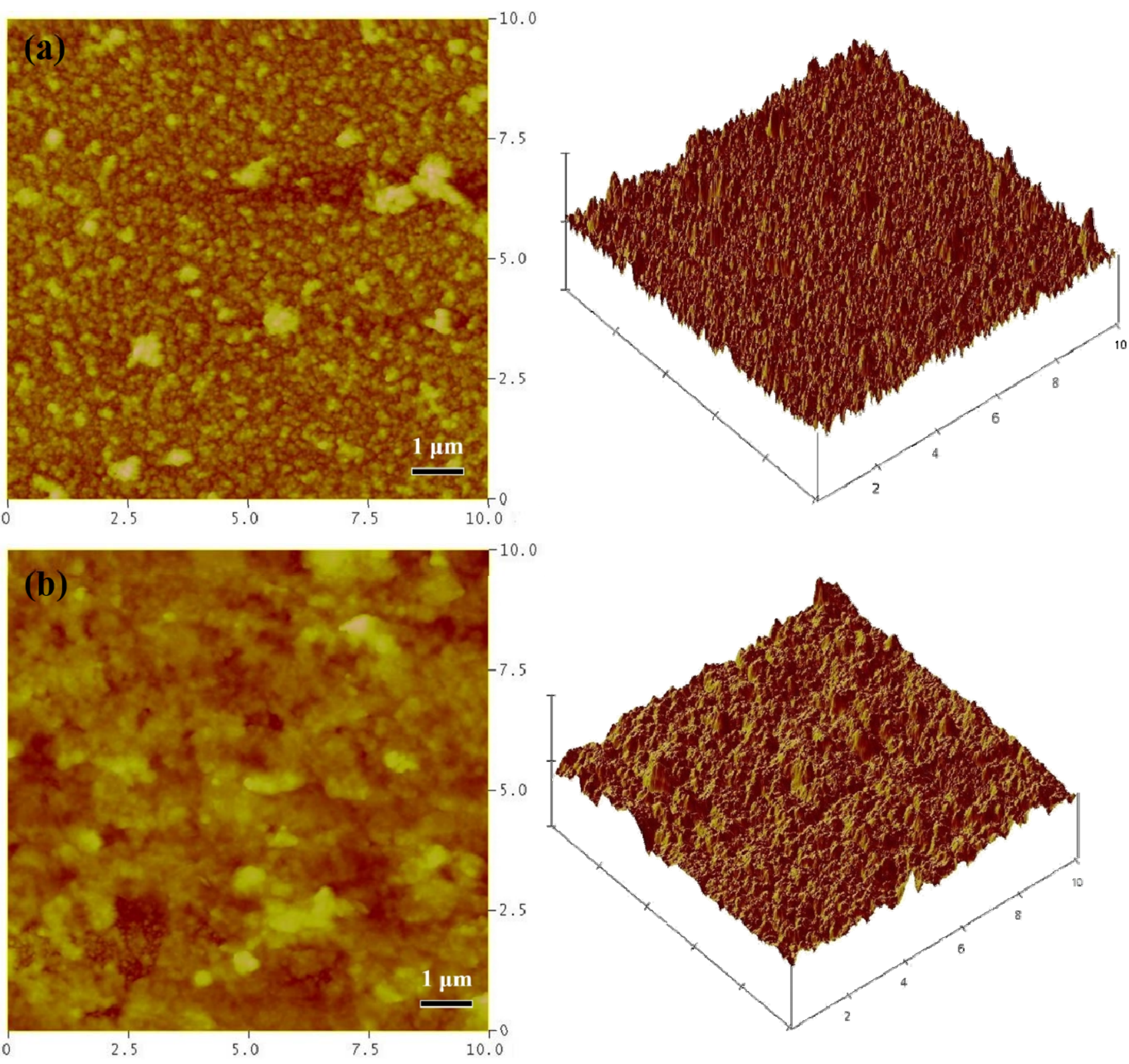

Figure S9. AFM images of (a) silica/(PS100-b-PLL50/PGA75)3 and (b) silica/(PS100- $b$ PLL50/PGA75)5 composite films coated onto glass substrate. 

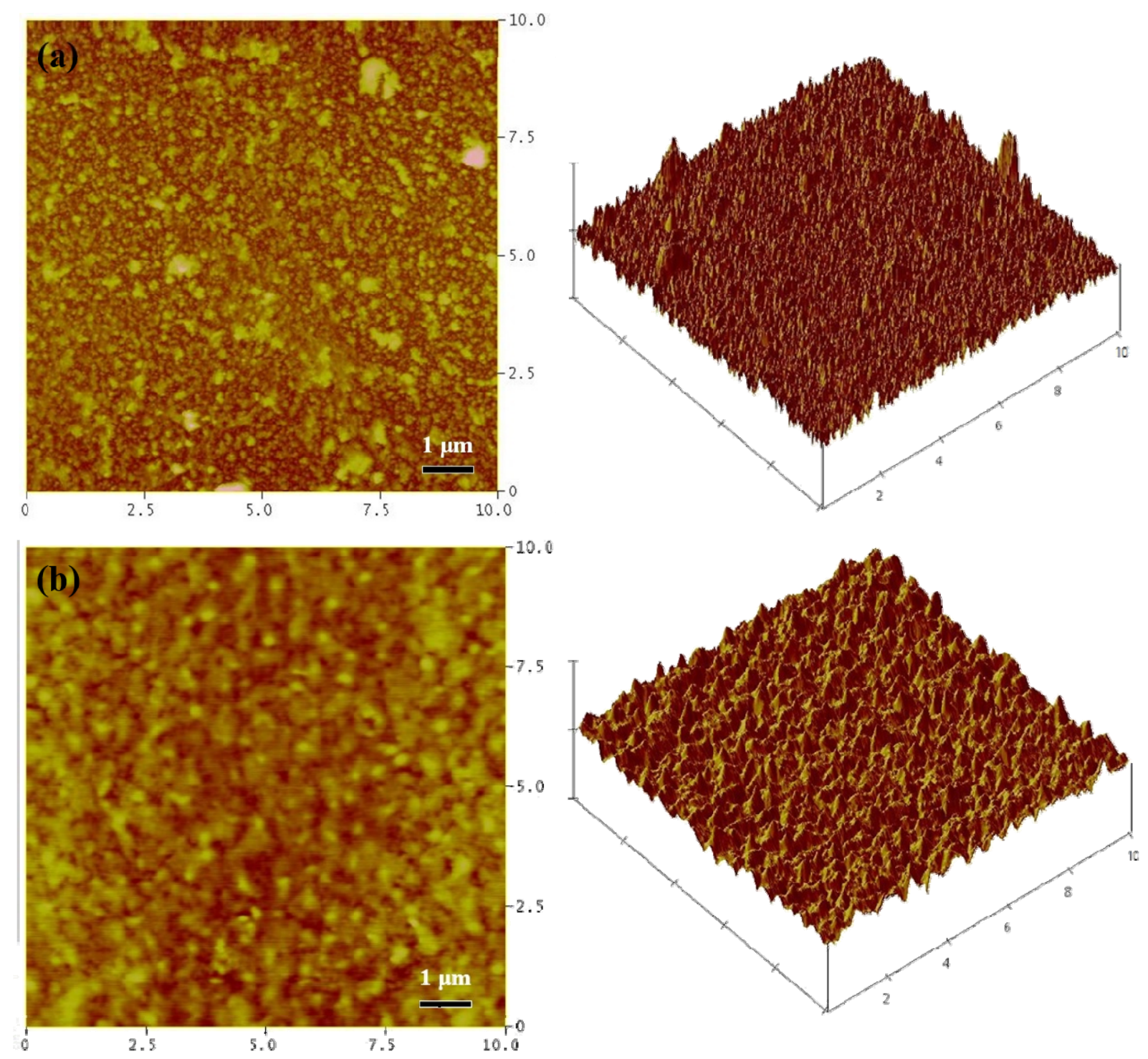

Figure S10. AFM images of silica/((PS 100$\left.)_{2}-b-\mathrm{PLL}_{50} / \mathrm{PGA}_{75}\right)_{3}$ composite films coated onto (a) glass and (b) PMMA substrates. 


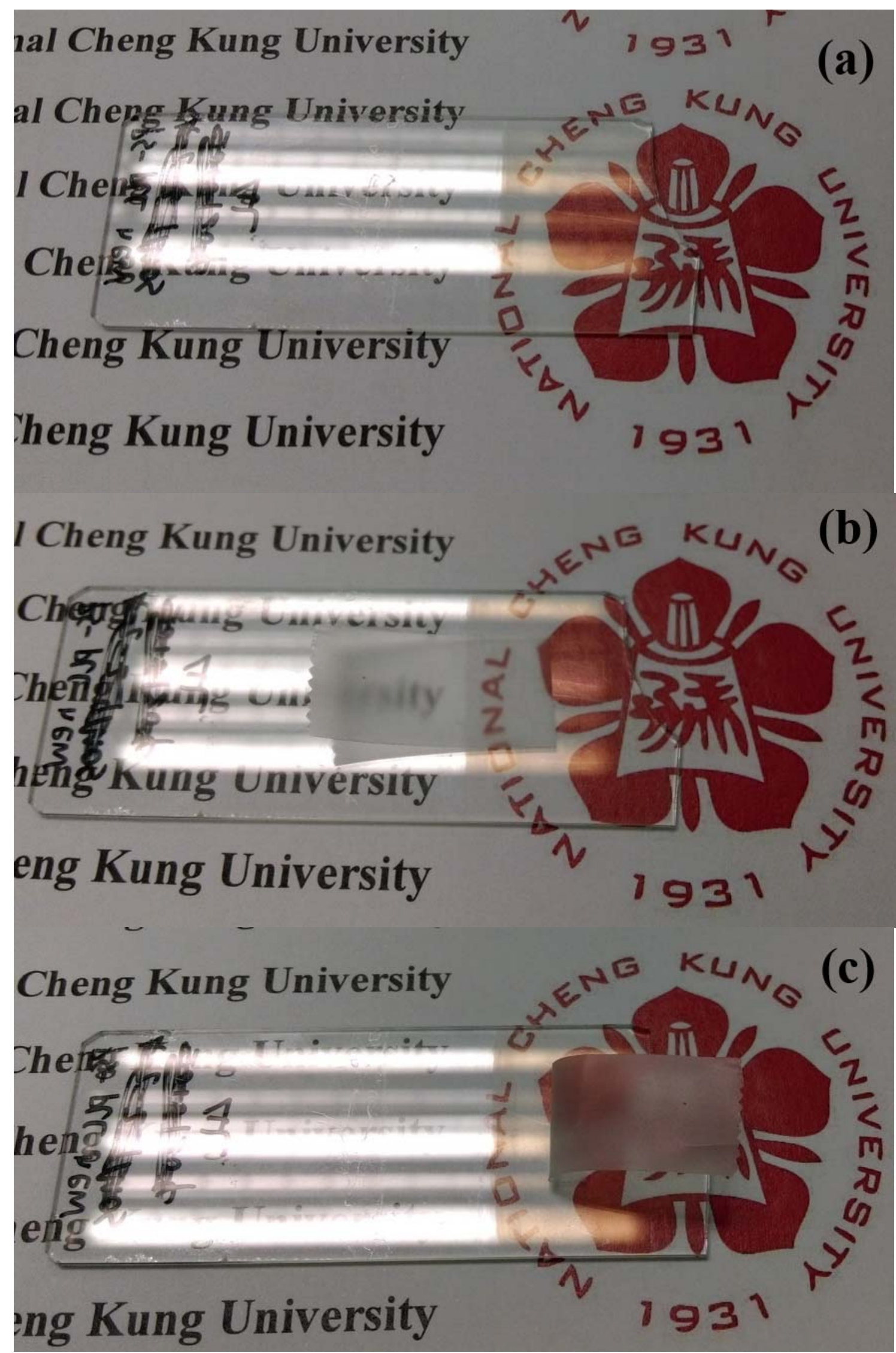

Figure S11. Adhesion test of silica/(PS $\left.100-b-\mathrm{PLL}_{50} / \mathrm{PGA}_{75}\right)_{4}$ composite film coated onto glass substrate using scotch tape. The coated glass substrate (a) without and (b, c) with scotch tape; (c) The scotch tape was peeled off from the coated substrate. 


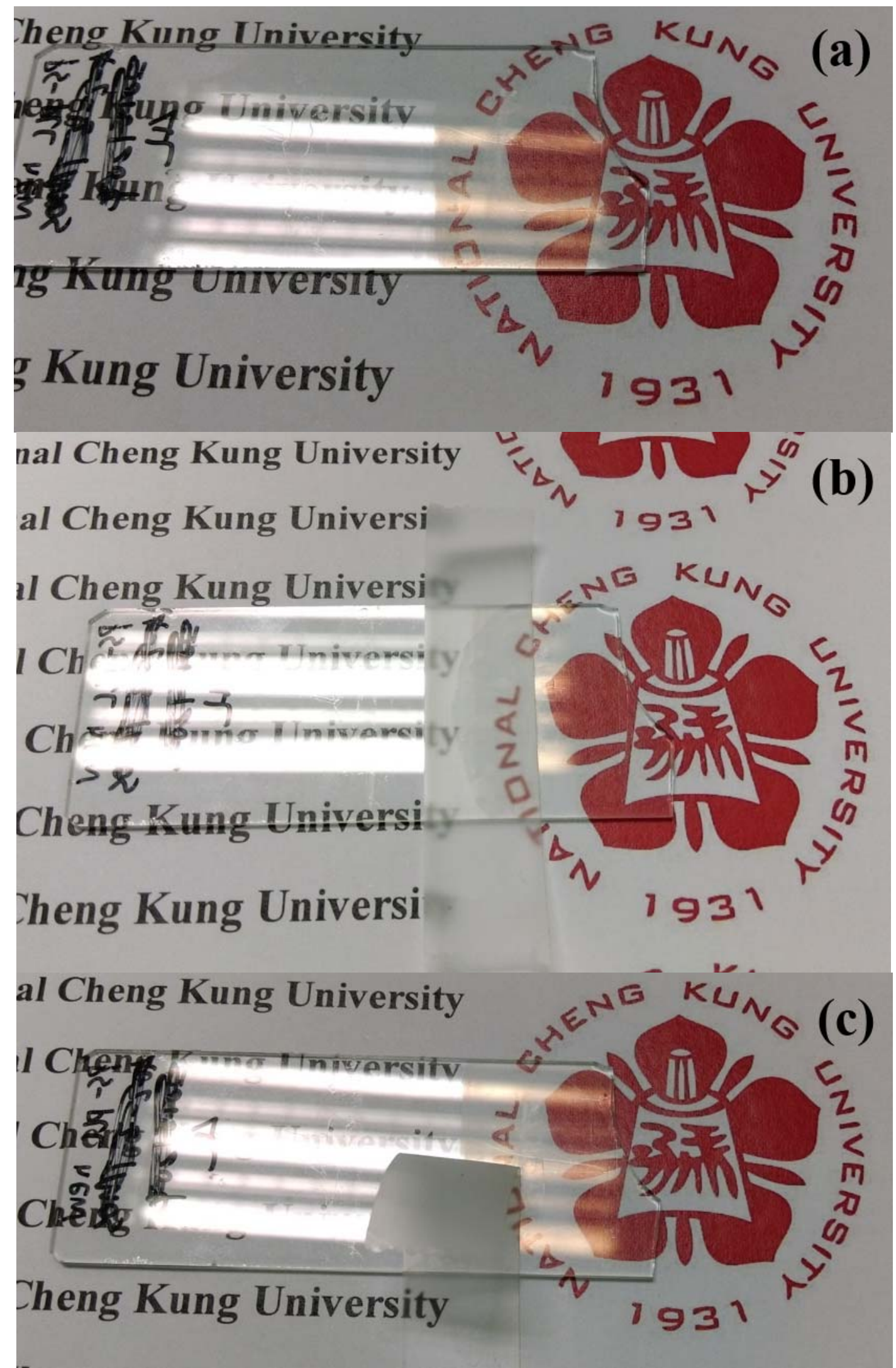

Figure S12. Adhesion test of silica/( $\left.\mathrm{PS}_{100}-b_{-} \mathrm{PLL}_{50} / \mathrm{PGA}_{75}\right)_{4}$ composite film coated onto glass substrate using scotch tape. The coated glass substrate (a) without and (b, c) with scotch tape; (c) The scotch tape was peeled off from the coated substrate. 